\title{
Local use of dexamethasone in the treatment of ocular myasthenia gravis
}

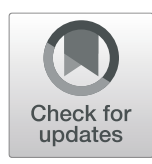

Minghua Shi ${ }^{*}$, Yingjia Ye, Junping Zhou, Aijiao Qin, Jing Cheng and Hongxing Ren

\begin{abstract}
Background: At present, patients with ocular myasthenia gravis (OMG) are typically treated with systemic drugs. We investigated the use of dexamethasone injected in the peribulbar region or extraocular muscle to treat patients with OMG.

Methods: Patients with OMG were given dexamethasone via peribulbar injection or direct injection into the main paralyzed extraocular muscles, once a week, for 4-6 weeks. The severity of diplopia, blepharoptosis, eye position, and eye movement were evaluated before and after treatment. The duration of follow-up time was $\geq 6$ months.

Results: Among the 14 patients with OMG who received this treatment, mean age was $38.7 \pm 29.7$ years. After treatment, symptoms were relieved in 12 patients (85.7\%), 1 patient (7.1\%) had partial response to treatment, and 1 patient (7.1\%) had no response. Two patients (14.2\%) experienced symptom recurrence during the follow-up period.

Conclusions: Dexamethasone peribulbar or extraocular muscle injection is effective in the treatment of patients with $O M G$ and may replace systemic drug therapy.

Trial registration: Chinese Clinical Trial Registry, ChiCTR2000038863, October 7, 2020.Retrospectively registered.

Keywords: Ocular myasthenia gravis, Strabismus, Corticosteroids, Dexamethasone, Local injection
\end{abstract}

\section{Background}

Myasthenia gravis (MG) is an autoimmune disease that mainly involves acetylcholine receptors (AchR) on the postsynaptic membrane at the neuromuscular junction. The annual incidence of MG is reported to range from 3 to 30 per million per year, with prevalence of approximately 150-300 per million [1-3]. About 60\% MG known as simple OMG [3-5]. This proportion is higher among children, reaching 71 to $93 \%[5,6]$.

In the past, even patients with OMG in whom symptoms were limited to the eyes were treated with systemic drugs, including acetylcholinesterase inhibitors, corticosteroids, immunosuppressants, immunomodulating agents and, recently, vascular growth factor inhibitors

\footnotetext{
* Correspondence: 13995559689@163.com

Department of Strabismus and Pediatric Ophthalmology, Wuhan Aier Eye Hospital (Hanyang), Wuhan 430020, China
}

[7-9]. Among these treatments, oral acetylcholinesterase inhibitors and corticosteroids were used most commonly [7-9]. Few patients underwent thymectomy or other types of surgery [10]. But any type of systemic medication is likely to induce adverse reactions.

Ophthalmologists seeking to treat autoimmune ocular diseases used various methods for drug delivery, including subconjunctival, hemispheric, and retrobulbar injections, as well as intravitreal administration, and achieved good therapeutic effects. These diseases include simple ocular inflammation and ocular inflammation caused by systemic disease [11]. Local treatment with topical corticosteroids has been recommended as first-line treatment for juvenile idiopathic arthritis (JIA)-associated uveitis, when the disease is mild and patients can be weaned relatively quickly off of steroid therapy $[12,13]$. The topical injection of hormone drugs such as triamcinolone

(c) The Author(s). 2020 Open Access This article is licensed under a Creative Commons Attribution 4.0 International License, which permits use, sharing, adaptation, distribution and reproduction in any medium or format, as long as you give appropriate credit to the original author(s) and the source, provide a link to the Creative Commons licence, and indicate if changes were made. The images or other third party material in this article are included in the article's Creative Commons licence, unless indicated otherwise in a credit line to the material. If material is not included in the article's Creative Commons licence and your intended use is not permitted by statutory regulation or exceeds the permitted use, you will need to obtain permission directly from the copyright holder. To view a copy of this licence, visit http://creativecommons.org/licenses/by/4.0/ The Creative Commons Public Domain Dedication waiver (http://creativecommons.org/publicdomain/zero/1.0/) applies to the data made available in this article, unless otherwise stated in a credit line to the data. 
acetonide or dexamethasone also has been used successfully for the treatment of thyroid-related ophthalmopathy $[14,15]$. Alkawas et al. compared the efficacy of peribulbar triamcinolone acetonide to oral prednisone in the treatment of thyroid-associated ophthalmopathy. In the group treated orally, the mean exophthalmometry measurement decreased from $23 \pm 1.86 \mathrm{~mm}$ before treatment to $19.08 \pm 1.16 \mathrm{~mm}$ after treatment. However, in the group that received peribulbar injections, mean exophthalmometry values before and after treatment were $22.6 \pm 1.98 \mathrm{~mm}$ and $18.6 \pm 0.996 \mathrm{~mm}$, respectively. Furthermore, compared with oral hormone treatment, local injections were associated with fewer side effects.

Based on these published findings, we speculate that local medication for OMG may effectively treat ocular symptoms, while decreasing the risk for side effects, compared with the use of systemic medication. This article explores the use of locally injected dexamethasone, a corticosteroid, for the treatment of patients with OMG.

\section{Methods}

Patients who came to our hospital during the period from August 2016 to May 2019 were diagnosed with OMG based on the symptoms presented and the results of the neostigmine test. If the neostigmine test was negative, a positive results on thymic computed tomography (CT), electromyography, or the acetylcholine receptor antibody(AChR-Ab)test was required. The exclusion criteria were systemic symptoms (e.g., muscular weakness below the neck), refusal to cooperate with the treatment plan, and compliance with follow-up. This study adhered to the Declaration of Helsinki, and was approved by our hospital Ethics Committee.

A detailed medical history was obtained for each patient. All patients underwent general and ocular examinations. The general examination included routine blood and urine tests, as well as measurements of blood sugar, blood lipid, liver and kidney function, thyroid function, erythrocyte sedimentation rate, rheumatoid factor, and C-reactive protein. Each patient also underwent slitlamp, fundus, and synoptophore examinations, as well as measurements of intraocular pressure and visual acuity. A four-hole lamp was used to check for diplopia, and the prism alternative cover test was performed to determine the degree of deviation. Blepharoptosis was classified as mild (upper eyelid margin covering $<1 / 2$ pupils with the patient looking straight ahead), severe (completely unable to open the eyelid fissure), or moderate (between "mild" and "severe"). Ocular motor duction was graded on a scale ranging from 0 to $-5(0$, normal; 5 , lack of muscle function; -1 to -4 , not reaching the midline, in $25 \%$ increments).

Before formal treatment was initiated, all patients and their families were given detailed information about their condition and various treatment methods, including the advantages and disadvantages of each. After an understanding of the risks involved was achieved, all patients or their parents signed an written informed consent form approved by the institutional Review Board. We also obtained explicit written informed consent to publish all data related to the study (including individual details, images, and videos) from the patients or their parents (for children $<18$ years of age).

All patients received local injections of dexamethasone in the peribulbar region or extraocular muscle, once a week, for 4-6 times. The site of injection was determined based on the patient's ocular signs. In the case of a clear limitation of ocular duction, dexamethasone was directly injected into the main paralyzed extraocular muscle. If the main symptom was ptosis, with no limitation of ocular duction, a peribulbar injection of dexamethasone was administered to the inferolateral orbital quadrant. Patients were closely observed with regard to ocular position and movement, diplopia and degree of blepharoptosis, visual acuity, intraocular pressure and general condition. If the symptoms did not improve after two injections, if the patient's condition worsened at any time, or if any sign of GMG (any muscle weakness below the neck or in the facial muscles except the orbicularis oculi) appeared, the treatment plan was discontinued, and the patient was transferred to the neurology department. After treatment, the patients were followed up monthly for 6 months, or at any sign of disease recurrence.

\section{Extraocular muscle injection}

Patients assigned to the extraocular muscle injections group received $0.5 \%$ dexamethasone $(0.2 \mathrm{~mL})$ and $2 \%$ lidocaine $(0.2 \mathrm{~mL})$. After topical anesthesia with proparacaine, the clinician disinfected the skin around the eye and the conjunctival surface with $5 \%$ povidone iodine. The eyelid was opened, and the paralyzed extraocular muscle was clamped with toothed forceps. Injections were administered with 30G needles, which were inserted at the point of extraocular muscle attachment, then advanced $8-10 \mathrm{~mm}$ along the muscle to inject dexamethasone directly into the muscle sheath.

\section{Peribulbar injection}

Patients assigned to the peribulbar injection group received $0.5 \%$ dexamethasone $(0.5 \mathrm{~mL})$, which was administered with an $27 \mathrm{G}$ needle. The drug was slowly injected inside the orbital rim of the inferolateral quadrant, posterior to the orbital septum.

\section{Statistical analysis}

Statistical analysis was performed with SPSS statistical software, version 17.0. The degree of strabismus was 
compared before vs. after treatment with the t-test. The relationship between the degree of ocular duction limitation and recovery time was tested with the bilateral Pearson correlation test.

\section{Results}

During the period from August 2016 to May 2019, 20 patients at our hospital were diagnosed with MG. Sixteen patients had OMG, and 4 patients had mild general myasthenia gravis (GMG). Four patients with GMG were transferred to the external neurology department. Two patients with OMG did not consent to receive treatment. The remaining 14 cases of OMG received the treatment regimen, including a 8-years old boy, who was successfully treated by local injection under surface anesthesia. Among them, 2 patients had an irregular history of medical treatment. Patient age ranged from 8 to 92 years (average, $38.7 \pm 29.7$ years). Average bestcorrected visual acuity (BCVA; log MAR) was $0.11 \pm$ 0.03 in the right eyes and $0.14 \pm 0.10$ in the left eyes.
All 14 patients had strabismus, diplopia, and ptosis. Four patients had headache, and neck weakness. The neostigmine test yielded positive test results in 12 cases. CT scans revealed thymic hyperplasia in 3 cases and AChR-Ab positive disease in 6 cases. See Table 1 for details.

Among 14 patients, 3 cases had normal ocular duction; 7 cases had adduction; 1 case had abduction; 3 cases had adduction and supraduction. The information related to each patient's ocular characteristics and the site of injection are detailed in Table 1 and summarized in Supplementary file 1.

\section{Treatment outcomes}

Patient 7, a 92-year-old female, did not significantly improve after receiving 2 injections in the area adjacent to the medial and superior rectus muscles. She was transferred to the neurology department. The exotropia and diplopia experienced by Patient 13, a 73-year-old female, resolved after treatment, but her blepharoptosis improved only slightly. The remaining 12 patients achieved

Table 1 General patient information

\begin{tabular}{|c|c|c|c|c|c|c|c|c|c|c|c|c|c|c|c|}
\hline Patient number & 1 & 2 & 3 & 4 & 5 & 6 & 7 & 8 & 9 & 10 & 11 & 12 & 13 & 14 & Average \\
\hline \multicolumn{16}{|l|}{ BCVA } \\
\hline od & 0.1 & 0.1 & 0.1 & 0.1 & 0.1 & 0.1 & 0.2 & 0.1 & 0.1 & 0.1 & 0.1 & 0.1 & 0.2 & 0.1 & $0.11 \pm 0.03$ \\
\hline os & 0.1 & 0.1 & 0.1 & 0.1 & 0.1 & 0.1 & 0.4 & 0.1 & 0.1 & 0.1 & 0.1 & 0.1 & 0.4 & 0.1 & $0.14 \pm 0.10$ \\
\hline Duration & 8 & 12 & 3 & 3 & 3 & 6 & 1 & 2 & 4 & 6 & 3 & 3 & 3 & 4 & $4.35 \pm 2.84$ \\
\hline Neostigmine test & + & + & + & + & + & + & + & + & - & + & - & + & + & + & \\
\hline Thymus CT & - & - & - & - & + & - & - & - & + & + & - & - & - & - & \\
\hline AchR-Ab & - & + & - & + & - & - & + & - & + & + & - & - & - & + & \\
\hline Systemic disease & No & No & No & No & No & No & No & No & No & No & No & No & No & No & \\
\hline History of treatment & No & No & No & Yes & No & No & No & No & No & No & No & No & No & Yes & \\
\hline Ptosis & Bilateral & Left & Right & Bilateral & Right & Left & Bilateral & Right & Bilateral & Right & Left & Right & Right & Bilateral & \\
\hline Diplopia & + & + & + & + & + & + & + & + & + & + & + & + & + & + & \\
\hline $\begin{array}{l}\text { Ocular Duction } \\
\text { Limitation }\end{array}$ & + & + & + & - & + & + & + & + & - & + & + & + & - & - & \\
\hline \multicolumn{16}{|c|}{ Deviation before treatment (PD) } \\
\hline horizontal ${ }^{a}$ & -40 & -30 & -30 & -20 & -60 & -30 & -30 & -40 & -20 & -40 & -25 & -35 & -20 & +20 & $-28.5 \pm 11.1$ \\
\hline vertical & 2 & 3 & 0 & 0 & 8 & 10 & 20 & 6 & 3 & 5 & 12 & 10 & 0 & 3 & $5.85 \pm 5.68$ \\
\hline Injection site & RMR & LMR & $\mathrm{RMR}$ & BMR & RMR & LMR & $\begin{array}{l}\text { LMR + } \\
\text { LSR }\end{array}$ & RMR & BMR & RMR & LMR & RMR & $\mathrm{RP}$ & RLR & \\
\hline Injection times & 6 & 4 & 4 & 4 & 6 & 4 & 2 & 4 & 4 & 5 & 4 & 4 & 4 & 4 & $4.23 \pm 1.01$ \\
\hline \multicolumn{16}{|c|}{ Deviation after treatment (PD) } \\
\hline horizontal $^{a}$ & -5 & -3 & -3 & 0 & -3 & -5 & -30 & -5 & -3 & -3 & -4 & 0 & -2 & +3 & $-4.92 \pm 7.38$ \\
\hline vertical & 0 & 2 & 2 & 3 & 0 & 5 & 10 & 0 & 0 & 0 & 5 & 2 & 0 & 0 & $2.07 \pm 2.92$ \\
\hline Follow up time(months) & 25 & 23 & 23 & 21 & 19 & 19 & - & 17 & 16 & 13 & 10 & 9 & 8 & 6 & $16.0 \pm 6.33$ \\
\hline Recurrence & NO & NO & NO & NO & NO & NO & - & NO & Yes & NO & NO & NO & NO & Yes & \\
\hline
\end{tabular}

Duration: time from symptom onset to presentation at our institution; $A C h R A b$ acetylcholine receptor antibody; $B C V A$ best-corrected visual acuity; $O D$ right eye; $O S$ left eye; $P D$ prism diopters; $R M R$ right medial rectus muscle: $L M R$ left medial rectus muscle; $B M R$ bilateral medial rectus muscles; $L S R$ left superior rectus muscle; $R P$ right peribulbar area; $R L R$ right lateral rectus muscle

${ }^{a}$ Average horizontal deviation before and after treatment (absolute value) 
good treatment results. Patient 4 and Patient 9 had intermittent exotropia without obvious limitations in duction; their symptoms resolved after a single injection. The other 9 patients with limited duction presented with a resolution of their ptosis, neck weakness, and headache symptoms after one-time treatment. Diplopia symptoms disappeared in all patients after 4 injections. However, the complete recovery of extraocular muscle strength was delayed in some patients. Patients 1, 5, and 10 received another 1-2 injections because persistent limitations in ocular duction. After 3 months of follow-up, ocular duction had returned to normal in these patients. Among the patients who ultimately recovered from ptosis, the time to recovery time was $\leq 1$ week. The average time to recovery from diplopia was $1.75 \pm 0.62$ weeks; the average time to recovery of ocular duction was $4.55 \pm 2.44$ weeks. The time to recovery of ocular duction was inversely correlated with the severity of the limitation $(R=0.13, P=0.739)$. The severity of ocular symptoms and recovery time are shown in Table 2.

\section{Recurrence}

One case (Patient 9) relapsed 1 year after recovery. The symptoms were alleviated after 4 local injections of dexamethasone. The condition is stable at present. A cured esotropia patient (Patients 14) developed exotropia and diplopia 6 weeks after withdrawal. After 4 injections of dexamethasone into the medial rectus muscles of both eyes, the symptoms were relieved once more. However, the patient's symptoms recurred again after 5 weeks. We did not believe that this patient was able to achieve drug-independent remission, so local injections were administered once per month. At present, the patient's symptoms are well controlled.

In short, among the 14 cases, 11 cases achieved drugindependent remission; 1 case achieved drug-dependent remission; 1 case improved; 1 case failed to improve. The overall cure rate was $85.7 \%$. No patient converted to GMG. The average horizontal deviation (absolute value) was $28.57 \pm 17.5 \mathrm{PD}$ before treatment and 4.92 \pm 7.38PD at the time of the last follow-up $(\mathrm{t}=-4.73, P<0.001)$. The average vertical deviation decreased from $5.85 \pm$ 5.68 PD before treatment to $2.07 \pm 2.92$ PD after treatment $(\mathrm{t}=-3.02, P=0.003)$. For details see Table 1 .

\section{Complications}

All patients had no local or systemic complications except subconjunctival hemorrhage caused by injection. Including decreased vision, increased peribulbar pressure, conjunctival and corneal lysis, obesity and so on.

\section{Representative cases \\ Case 1}

Patient 6 was a 73-year-old male patient who had experienced diplopia and blepharoptosis for 1 month, with no headache, neck weakness, or other symptoms. Upon physical examination, the main signs were left eyelid droop and large-angle exotropia, accompanied by a mild limitation in supraduction. Dexamethasone was injected into the left medial rectus muscle. The patient's

Table 2 Symptom severity and recovery time

\begin{tabular}{|c|c|c|c|c|c|}
\hline \multirow{2}{*}{$\begin{array}{l}\text { Patient } \\
\text { no. }\end{array}$} & \multicolumn{2}{|l|}{ Symptom severity } & \multicolumn{3}{|c|}{ Recovery time (weeks) } \\
\hline & Ptosis (Side: Degree) & Ocular duction (Eye: Duction, Degree) & Ptosis & Diplopia & Ocular duction \\
\hline 1 & Right: Moderate; Left: Mild & OD, Adduction, - 3 & 1 & 3 & 8 \\
\hline 2 & Left: Moderate & OS: Adduction, -1 & 1 & 2 & 4 \\
\hline 3 & Right: Moderate & OD: Adduction, -2 & 1 & 2 & 3 \\
\hline 4 & Bilateral: Mild & Normal & 1 & 1 & - \\
\hline 5 & Right: Moderate & OD: Adduction, -3 & 1 & 2 & 8 \\
\hline 6 & Left: Moderate & OS: Adduction, - 3 mm; Supraduction, -1 & 1 & 2 & 4 \\
\hline 7 & Right: Mild; Left: Severe & OS: Adduction, -1 ; Supraduction, -2 & No improvement & No improvement & No improvement \\
\hline 8 & Right: Mild & OD: Adduction, -1 & 1 & 1 & 2 \\
\hline 9 & Bilateral: Mild & Normal & 1 & 1 & - \\
\hline 10 & Right: Moderate & OD: Adduction, -3 & 1 & 2 & 6 \\
\hline 11 & Left: Mild & OS: Adduction, -2 ; Supraduction, -1 & 1 & 2 & 3 \\
\hline 12 & Right: Moderate & OD: Adduction, -2 & 1 & 2 & 3 \\
\hline 13 & Right: Severe & Normal & Improvement & 1 & - \\
\hline 14 & Bilateral: Moderate & OD: Abduction, -3 & 1 & 3 & 5 \\
\hline
\end{tabular}


blepharoptosis resolved within 1 week; diplopia resolved within 2 weeks; eye movement returned to normal in 4 weeks. No recurrence was noted during the follow-up period. Photographs of this case (before treatment and 1 week and 1 month after treatment, respectively) are shown in Fig. 1.

\section{Case 2}

Patient 1 was a 14-year-old female who presented with 8-month history of blepharoptosis and diplopia, accompanied by neck weakness, headache, and inability to sustain visual focus. Main signs: moderate blepharoptosis in the right eye, mild blepharoptosis in the left eye; exotropia (right eye adduction with inability to cross the midline). Dexamethasone was injected into the right medial rectus muscle. One week later, the patient's ptosis, headache, and neck weakness had resolved. After 3 weeks, the diplopia disappeared, and eye position was orthophoria. After 4 weeks, rotation of the right eye remained insufficient. Dexamethasone was injected another two times. After 2 months, eye movement had returned to normal, with no recurrence of symptoms over 2 years of follow-up. Photographs of this case (before treatment and 1 week, 1 month, and 3 months after treatment) are shown in Fig. 2.

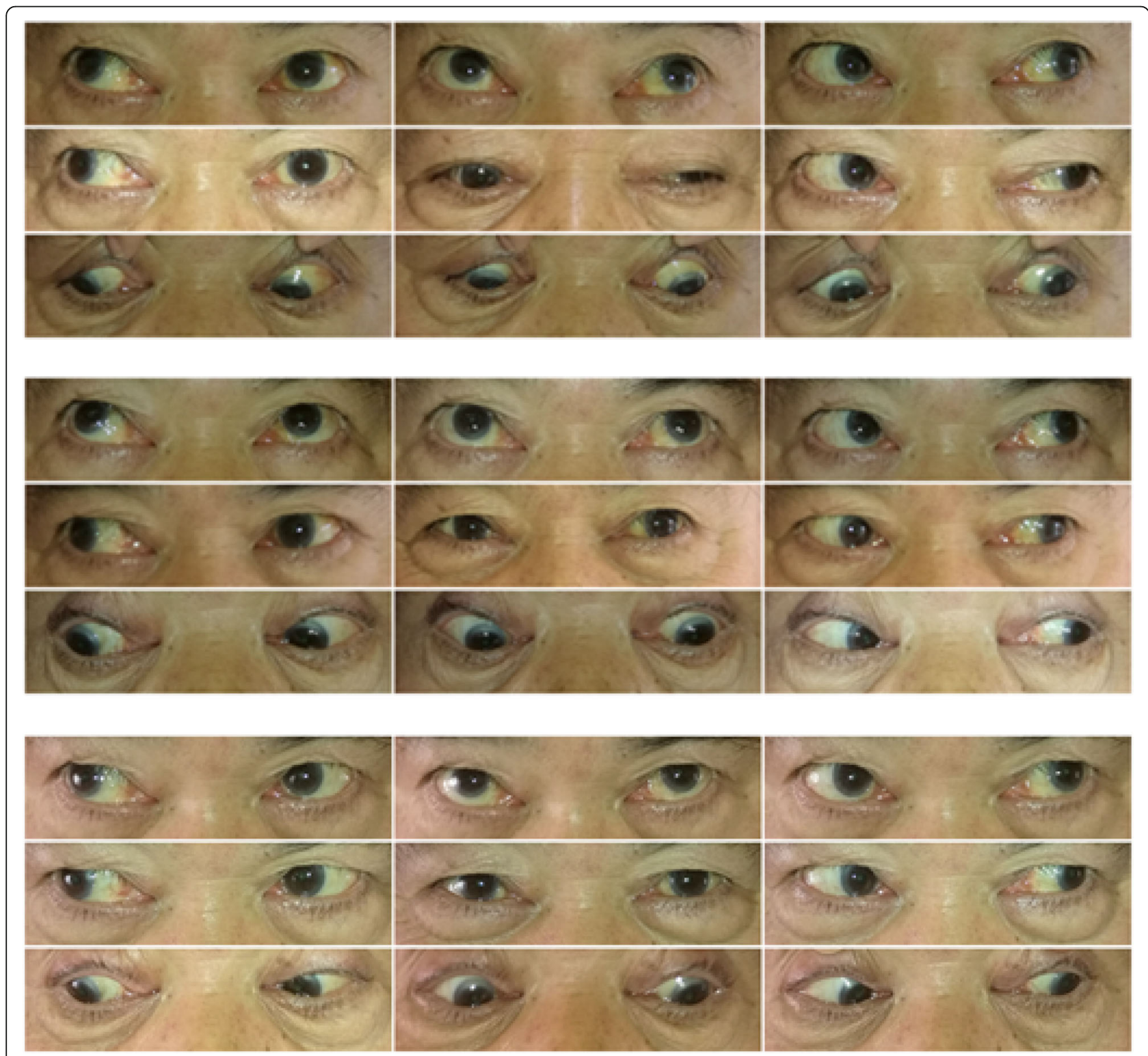

Fig. 1 Eye position in Patient 6. The photographs of eye position from top to bottom: before treatment, 1 week, 1 month after treatment 


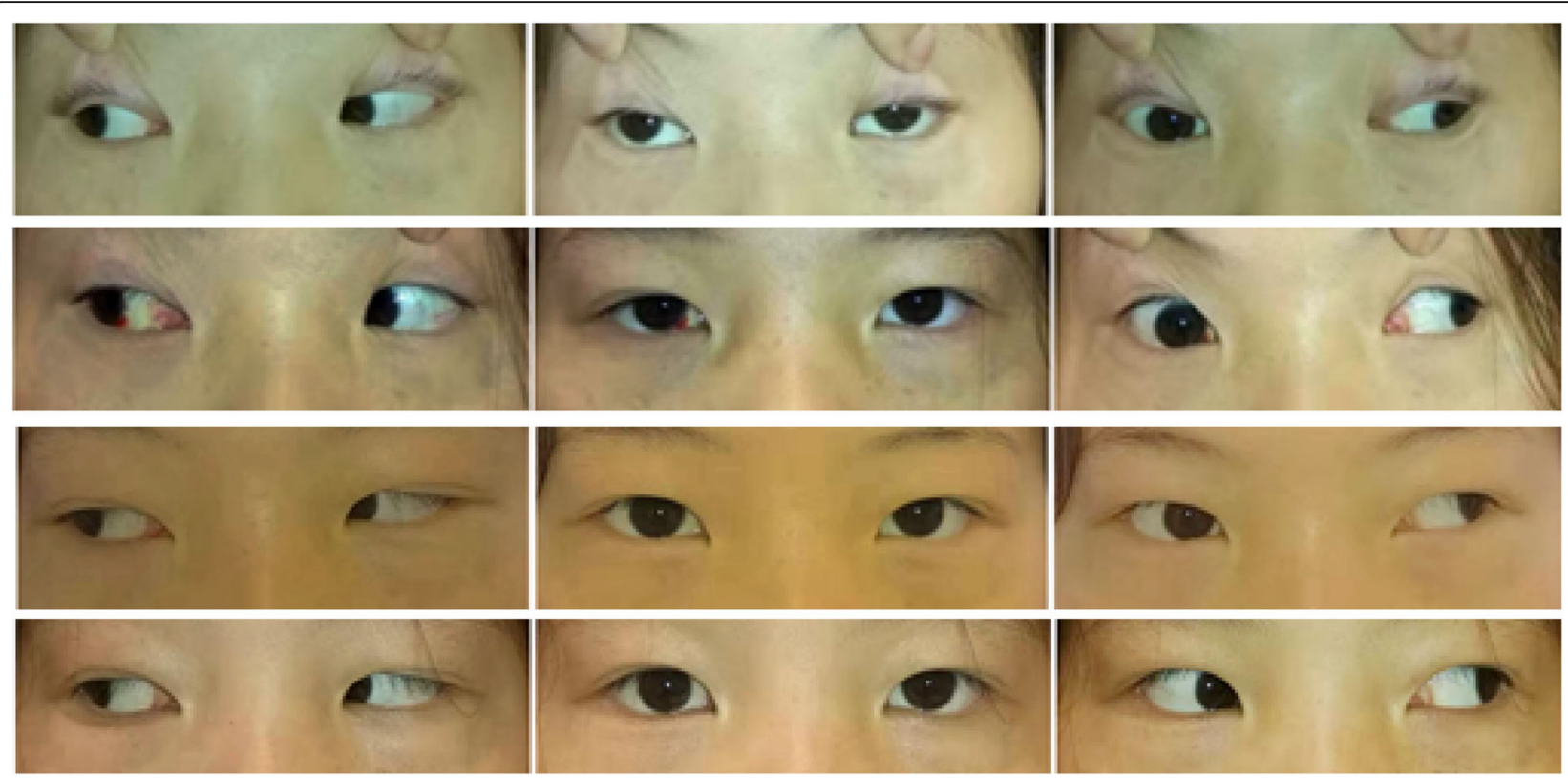

Fig. 2 Eye position in patient 1. The photographs of eye position from top to bottom: before treatment, 1 week, 1 month, and 3 months after treatment

\section{Discussion}

A review of the medical literature did not reveal any reports about the local used of medication in the treatment of OMG. Whether uveitis is caused by systemic disease or thyroid-related ophthalmopathy, local inflammation is a contributing factor. Local inflammation may respond to anti-inflammatory medication. Notably, myasthenia is not the direct result of inflammation but, rather, an antibody-mediated weakness. The symptoms associated with myasthenia are caused by antibody production that is not necessarily localized, so local injections of corticosteroid are not expected to reduce the production of circulating antibodies to the acetylcholine receptor. This may be the main reason why few studies published to date have investigated the administration of local treatment for MG. However, Agius maintain that OMG may be associated with ocular muscle antigen structure and/or reduced susceptibility to risk factors [16]. Soltys et al. [17] reported that, in autoimmune MG, the neuromuscular junctions in extraocular muscles are more susceptible to complement-mediated injury than are those of other muscles. Local factors thus appear to be a major cause of OMG. Although numerous issues remain to be elucidated, the local injection of dexamethasone appears to be an effective treatment option. The local use of dexamethasone is simple, convenient, and almost risk free.

More importantly, local injections of dexamethasone have achieved good outcomes in clinical practice. In our prospective small-scale case study, which included 14 cases, 11 cases achieved drug-independent remission; 1 case achieved drug-dependent remission, 1 case improved; 1 case failed to improve. The overall cure rate was $85.7 \%$. Although the mechanism of local hormone therapy for OMG remain unclear, the clinical effect cannot be denied.

Among numerous studies have investigated oral drug therapy for OMG, few have examined strabismus, ptosis, or quantified measurements of the range of eye movement as outcomes $[6,18,19]$. Kupersmith et al. [18] reported on the use of prednisone and pyridostigmine for the treatment of patients with OMG. One month later after treatment, the degree of strabismus had not changed significantly in the pyridostigmine group and had decreased from 12.2 PD to 5.5 PD in the prednisone group. Among 51 patients who responded to prednisone treatment, 26 experienced symptom recurrence as the dose of prednisone was decreased. At 2 years of followup, only 12 of 55 patients in the prednisone group reported that symptoms were completely relieved. No patient in the pyridostigmine group was completely relieved. Park et al. [19] followed 20 patients with MG who had obvious paralytic strabismus as the initial symptom for $45.4 \pm 39.7$ months. After systemic drug therapy (hormone and cholinesterase inhibitor), only 6 patients $(21.4 \pm 11.1)$ had responded well to treatment and reported the disappearance of diplopia. Four patients (14.3\%) had partial reactions, and 18 cases (64.3\%) had slight or no response to treatment; 10 cases (35.7\%) continued to suffer from strabismus of $>15$ PD. Six cases underwent strabismus surgery. Vanikieti et al. [6] performed a retrospective study of the effect of oral 
prednisone and/or pyridostigmine for OMG in children. Only $13(21.67 \%)$ of 60 children with blepharoptosis achieved drug-independent remission, and only 3 (7.9\%) of 38 patients with ophthalmoplegia achieved drugindependent remission. About 50\% of patients responded slightly or not at all to oral medication. We summary of the results of this study and previous reports of oral hormonal therapy for OMG in Table 3.In contrast to those previous reports on the use of oral drugs, our study show that local injection of dexamethasone has better treatment result for OMG.

In our study, we preferred directly inject the drug into the affected extraocular muscles, typically the medial rectus, and investigated the duration of remission for various symptoms. We believe that this approach may help to identify the optimal therapeutic approach with which to accelerate recovery from extraocular paralysis. Among the patients who ultimately recovered from ptosis, the time to recovery time was $\leq 1$ week. The average time to recovery from diplopia was $1.75 \pm 0.62$ weeks; the average time to recovery of ocular duction was $4.55 \pm 2.44$ weeks. The recovery of extraocular paralysis is still the most difficult, which may take several months. We found that the recovery of extraocular paralysis is the most difficult, which may take several months, and the recovery time is related to the degree of muscle paralysis. The recovery time is related to the degree of muscle paralysis. Compared with systemic steroids, local dexamethasone injections have a faster onset in OMG patients. Oral steroid-induced clinical improvement usually begins within 2 to 4 weeks, with marked improvement requiring 6-8 weeks [20].

Notably, although the direct injection of extraocular muscles was chosen, the sequence of symptom recovery observed in patients of our study was similar to that observed in patients who received oral drug therapy $[6,18,19,21]$.we also noted the neck muscle farthest from the injection point recovered fastest. We sought to identify the reason for this phenomenon. Nan et al. [22] reported that a single subTenon injection of triamcinolone acetonide (TA) was able to diffuse throughout the globe, including the aqueous, irisciliary body, vitreous, neuroretina, retinal pigment epithelium, and choroid, with therapeutic concentrations maintained for at least 30 days. Roesel et al. [23] observed similar results for the use of periocular corticosteroid injections, administered via the sub-Tenon route or as an orbital floor injection, for the treatment of uveitis. Based on the above research, we speculate that periocular corticosteroid injections could easily diffuse into adjacent muscle tissues and thus reach therapeutic concentrations. Recent studies have reported that high-dose intravenous methylprednisolone therapy in patients with OMG [24] or mild GMG [25] achieves faster improvement with better efficacy than oral prednisone. Dexamethasone injection into the periocular or extraocular muscles can also reach other parts of the body through circulating blood. This capacity for diffusion may explain the rapid relief of neck-related symptoms observed in this study. Sub-Tenon injections may achieve the same treatment effects as extraocular muscle injections while reducing risk for muscle hemorrhage and local injury.

Although most of the patients had good results, we noticed that two elderly patients with severe blepharoptosis had poor results (Patients 7 and 13). In addition to the fact that some patients are not sensitive to hormones, we also note that the results of systemic oral medication therapy show that the treatment of OMG in children seems to be better than that in older people [6]. Whether the same problem exists in local therapy remains to be seen further.

For OMG that is treated with systemic medication, continued corticosteroid therapy is typically necessary to prevent recurrence and conversion to GMG. Considering the side effects of hormones, we did not administer continuous injection therapy to patients whose symptoms had resolved. In this study, 10 of 14 patients (71.3\%) remained stable during the follow-up period after the treatment was stopped. Some studies suggest that patients who receive immune interval therapy during the early stage of OMG are less likely to develop systemic disease [18, 26-29]. Agius [16] reported that GMG may be due to increased antibody production and the expansion of antigenic molecular targets. The duration of the initial phase of immune attack on the neuromuscular junction may be an important determinant of disease severity. We speculate that the effectiveness of topical corticosteroids in alleviating OMG symptoms

Table 3 Summary of the results of this study and previous reports of oral hormonal therapy for OMG

\begin{tabular}{|c|c|c|c|c|}
\hline Author & Drug and treatment objects & Follow-up Time & $\begin{array}{l}\text { Number } \\
\text { of cases }\end{array}$ & $\begin{array}{l}\text { Complete remission rate at the } \\
\text { end of follow-up }\end{array}$ \\
\hline Mark J. Kupersmith [16] & Prednisone for OMG & 2 years & 55 & 12 patients(21.8\%) \\
\hline Kyung-Ah Park [17] & $\begin{array}{l}\text { prednisone and/or azathiorpine for } \\
\text { Initial MG with diplopia }\end{array}$ & $45.4 \pm 39.7$ months & 28 & 6 patients $(21.4 \%)$ \\
\hline Kavin Vanikieti [6] & $\begin{array}{l}\text { prednisone and/or pyridostigmine } \\
\text { for juvenile } \mathrm{OMG}\end{array}$ & 95 months & 62 & $\begin{array}{l}\text { Blepharoptosis:13 of } 60(21.67 \%) \text {; } \\
\text { ophthalmoplegia:3of } 38 \text { (7.9\%) }\end{array}$ \\
\hline Our study & $\begin{array}{l}\text { Dexamethasone peribulbar or } \\
\text { extraocular muscle injection for OMG }\end{array}$ & $16.0 \pm 6.33$ months & 14 & 11 patients(78.5\%) \\
\hline
\end{tabular}


may reduce the possibility of recurrence and aggravation. The dramatic results of this study may also reflect a statistical error caused by the short observation time and the small number of cases. In conclusion, the longterm effects of local hormone therapy on OMG require further study.

This study had some limitations. Firstly, the mechanism of local hormone injection in the treatment of OMG is not clear. Secondly, there is no clinical comparison with systemic drugs. In addition, the number of cases included in this study is small. As a systemic immune disease, MG commonly persist over time, despite temporary remission. Therefore, further studies will be necessary to determine the optimal site to be used for injection, the optimal time interval between injections and the optimal course of treatment. The stability of the curative effect achieved, the recurrence rate, and the rate of conversion will need to investigated on a larger scale and for a longer period of time.

\section{Conclusion}

In our small, prospective study, the local injection of dexamethasone in the treatment of OMG achieved good short-term results, supporting its use as a partial replacement for oral drug therapy. However, its mechanism still needs to be explored, and larger clinical controlled studies are also needed.

\section{Supplementary information}

The online version contains supplementary material available at https://doi. org/10.1186/s12886-020-01697-2

Additional file 1: Table S1. The Summary of patient characteristics and injection sites. (DOCX $13 \mathrm{~kb}$ )

\section{Abbreviations}

MG: Myasthenia gravis; OMG: Ocular myasthenia gravis; GMG: General myasthenia gravis; JIA: Juvenile idiopathic arthritis; CT: Computed tomography; AChR-Ab: Acetylcholine receptor antibody; MRI: Magnetic resonance imaging; PD: Prism diopters; SE: Spherical equivalents; BCVA: Bestcorrected visual acuity; OD: Right eye; OS: Left eye; RMR: Right medial rectus muscle; LMR: Left medial rectus muscle; BMR: Bilateral medial rectus muscles; LSR: Left superior rectus muscle; RP: Right peribulbar area; RLR: Right lateral rectus muscle

\section{Acknowledgements}

Not applicable.

\section{Authors' contributions}

MS conceived and designed the study. $Y Y, J Z, A Q, J C, H R$ participated in information gathering and editing, analyzed and interpreted all the data.MS wrote the first draft of manuscript. YY reviewed and edited the manuscript. MS reviewed and approved the final the version published. All authors read and approved the final manuscript.

\section{Funding}

This study was supported in part by Research Fund of Aier Eye Hospital Group, Project No: AFM1078D1.The funders had no role in study design, data collection and analysis, decision to publish or preparation of the manuscript. None of authors have any financial interest in any of the material described herein.

\section{Availability of data and materials}

The data are available from the corresponding author upon reasonable request.

\section{Ethics approval and consent to participate}

This study was performed in accordance with the Declaration of Helsinki and was approved by the Ethics Committee of Wuhan Aier Eye Hospital(Hanyang), China (2016IRBKYA022). Written informed consent was obtained from each patient or their parents (for children $<18$ years of age) prior to participation in the study.

\section{Consent for publication}

We have obtained explicit written informed consent to publish all data (including individual details, images, and videos) related to the study from patients or their parents.

\section{Competing interests}

The authors declare that they have no competing interests.

Received: 4 March 2020 Accepted: 14 October 2020

Published online: 28 October 2020

\section{References}

1. McGrogan A, Sneddon S, de Vries CS. The incidence of myasthenia gravis: a systematic literature review. Neuroepidemiology. 2010;34(3):171-83.

2. Casetta I, Groppo E, De Gennaro R, Cesnik E, Piccolo L, Volpato S, Granieri E. Myasthenia gravis: a changing pattern of incidence. J Neurol. 2010;257(12): 2015-9.

3. Benamer HT, Bredan A. The epidemiology of myasthenia gravis in Arab countries: a systematic review. Muscle Nerve. 2015;51(1):144-5.

4. Gilhus NE, Verschuuren JJ. Myasthenia gravis: subgroup classification and therapeutic strategies. Lancet Neurol. 2015;14(10):1023-36.

5. Huang X, Liu WB, Men LN, Feng HY, Li Y, Luo CM, Qiu L. Clinical features of myasthenia gravis in southern China: a retrospective review of 2,154 cases over 22 years. Neurol Sci. 2013:34(6):911-7.

6. Vanikieti K, Lowwongngam K, Padungkiatsagul T, Visudtibhan A, Poonyathalang A. Juvenile ocular myasthenia gravis: presentation and outcome of a large cohort. Pediatr Neurol. 2018;87:36-41.

7. Luchanok U, Kaminski HJ. Ocular myasthenia: diagnostic and treatment recommendations and the evidence base. Curr Opin Neurol. 2008;21(1):8-15.

8. Fortin $\mathrm{E}$, Cestari DM, Weinberg DH. Ocular myasthenia gravis: an update on diagnosis and treatment. Curr Opin Ophthalmol. 2018;29(6):477-84.

9. Mantegazza R, Bonanno S, Camera G, Antozzi C. Current and emerging therapies for the treatment of myasthenia gravis. Neuropsychiatr Dis Treat. 2011;7:151-60

10. Roberts PF, Venuta F, Rendina E, De Giacomo T, Coloni GF, Follette DM, Richman DP, Benfield JR. Thymectomy in the treatment of ocular myasthenia gravis. J Thorac Cardiovasc Surg. 2001;122(3):562-8.

11. Tempest-Roe S, Joshi L, Dick AD, Taylor SR. Local therapies for inflammatory eye disease in translation: past, present and future. BMC Ophthalmol. 2013; 13(1):39.

12. Foeldvari I. Ocular involvement in juvenile idiopathic arthritis: classification and treatment. Clin Rev Allergy Immunol. 2015;49(3):271-7.

13. Heiligenhaus A, Michels H, Schumacher C, Kopp I, Neudorf U, Niehues T, Baus H, Becker M, Bertram B, Dannecker G, et al. Evidence-based, interdisciplinary guidelines for anti-inflammatory treatment of uveitis associated with juvenile idiopathic arthritis. Rheumatol Int. 2012;32(5):1121-33.

14. Lee JM, Lee H, Park M, Baek S. Subconjunctival injection of triamcinolone for the treatment of upper lid retraction associated with thyroid eye disease. J Craniofac Surg. 2012;23(6):1755-8.

15. Alkawas AA, Hussein AM, Shahien EA. Orbital steroid injection versus oral steroid therapy in management of thyroid-related ophthalmopathy. Clin Exp Ophthalmol. 2010;38(7):692-7.

16. Agius MA. Treatment of ocular myasthenia with corticosteroids: yes. Arch Neurol. 2000;57(5):750-1.

17. Soltys J, Gong B, Kaminski HJ, Zhou Y, Kusner LL. Extraocular muscle susceptibility to myasthenia gravis: unique immunological environment? Ann N Y Acad Sci. 2008;1132:220-4.

18. Kupersmith MJ, Ying G. Ocular motor dysfunction and ptosis in ocular myasthenia gravis: effects of treatment. Br J Ophthalmol. 2005:89(10): 1330-4. 
19. Park KA, Oh SY. Treatment for diplopia in patients with myasthenia gravis. Graefes Arch Clin Exp Ophthalmol. 2013;251(3):895-901.

20. Sghirlanzoni A, Peluchetti D, Mantegazza R, Fiacchino F, Cornelio F. Myasthenia gravis: prolonged treatment with steroids. Neurology. 1984; 34(2):170-4

21. Bever CJ, Aquino AV, Penn AS, Lovelace RE, Rowland LP. Prognosis of ocular myasthenia. Ann Neurol. 1983;14(5):516-9.

22. Nan K, Sun S, Li Y, Qu J, Li G, Luo L, Chen H, Cheng L. Characterisation of systemic and ocular drug level of triamcinolone acetonide following a single sub-Tenon injection. Br J Ophthalmol. 2010;94(5):654-8.

23. Roesel M, Heinz C, Koch JM, Heiligenhaus A. Comparison of orbital floor triamcinolone acetonide and oral prednisolone for cataract surgery management in patients with non-infectious uveitis. Graefes Arch Clin Exp Ophthalmol. 2010;248(5):715-20.

24. Ozawa Y, Uzawa A, Kanai T, Oda F, Yasuda M, Kawaguchi N, Himuro K, Kuwabara S. Efficacy of high-dose intravenous methylprednisolone therapy for ocular myasthenia gravis. J Neurol Sci. 2019:402:12-5.

25. Sugimoto T, Ochi K, Ishikawa R, Tazuma T, Hayashi M, Mine N, Naito H, Nomura E, Kohriyama T, Yamawaki T. Initial deterioration and intravenous methylprednisolone therapy in patients with myasthenia gravis. J Neurol Sci. 2020;412:116740

26. Sommer N, Sigg B, Melms A, Weller M, Schepelmann K, Herzau V, Dichgans J. Ocular myasthenia gravis: response to long-term immunosuppressive treatment. J Neurol Neurosurg Psychiatry. 1997;62(2):156-62.

27. Kupersmith MJ, Latkany R, Homel P. Development of generalized disease at 2 years in patients with ocular myasthenia gravis. Arch Neurol. 2003;60(2): 243-8.

28. Mee J, Paine M, Byrne E, King J, Reardon K, O'Day J. Immunotherapy of ocular myasthenia gravis reduces conversion to generalized myasthenia gravis. J Neuroophthalmol. 2003;23(4):251-5.

29. Monsul NT, Patwa HS, Knorr AM, Lesser RL, Goldstein JM. The effect of prednisone on the progression from ocular to generalized myasthenia gravis. J Neurol Sci. 2004;217(2):131-3.

\section{Publisher's Note}

Springer Nature remains neutral with regard to jurisdictional claims in published maps and institutional affiliations.

Ready to submit your research? Choose BMC and benefit from:

- fast, convenient online submission

- thorough peer review by experienced researchers in your field

- rapid publication on acceptance

- support for research data, including large and complex data types

- gold Open Access which fosters wider collaboration and increased citations

- maximum visibility for your research: over $100 \mathrm{M}$ website views per year

At $\mathrm{BMC}$, research is always in progress.

Learn more biomedcentral.com/submissions 